\title{
Current physical activity and sports history of children 11 to 19 years old at high schools in Prague
}

\author{
Lukáš Babický ${ }^{1}$, Tereza Nováková ${ }^{1, *}$, Jan Vávra ${ }^{2}$, Lenka Satrapová ${ }^{1}$
}

1 Department of Physiotherapy, Faculty of Physical Education and Sports, Charles University, Prague, Czech Republic

2 Department of Probability and Mathematical Statistics, Faculty of Mathematics and Physics, Charles University, Prague, Czech Republic

* Corresponding author: tnovakova@ftvs.cuni.cz

\section{ABSTRACT}

Objectives. Objective of this study/thesis/work was to analyse the level of free time physical activity and its specifics on a sample of the adolescent population. To goal was to analyze the historical factor in each proband and its effect on the activity development. The analysis included information spanning from the initial experience with organized physical activity. The results of the survey are further compared with the conclusions of previous studies on the issue.

Methods. A total of 563 respondents ( 235 boys and 328 girls) from grammar schools in Prague participated in the research. Data were obtained using a questionnaire survey (computer assisted web interviewing (AWI) based on preliminary research and evaluated using MS Excel, GraphPad Prism and mathematical software R.

Results. The preference of just one sport (63.8\%) was found in the examined population. Predominant frequency of trainings was 2 to 4 per week (61.2\%). The vast majority (93.6\%) stated that they participated in fundamental movement training at a younger school age. More than half (61\%) experienced pain or injury during physical activity, especially in the lower limbs (61.9\%). The main factor in the termination of physical activity were psychosocial reasons (76.9\%). Increasing age has not been shown as a factor leading to reduction of physical activity in children. On the contrary, the frequency of activity increased as the children aged $(p=0.02)$. There was no significant dependence of the current activity on the completion of fundamental movement training $(p=0.08)$, nor was the confirmation of a general trend of higher activity of boys compared to girls $(p=0.64)$.

\section{KEYWORDS}

physical activity; adolescence; fundamental movement training; injury; pain

D0I

$10.14712 / 23366052.2020 .10$

(c) 2020 The Authors. This is an open-access article distributed under the terms of the Creative Commons Attribution License (http://creativecommons.org/licenses/by/4.0), which permits unrestricted use, distribution, and reproduction in any medium, provided the original author and source are credited. 


\section{INTRODUCTION}

With the rapid development of information technology, there is an ongoing discussion of its effects on decreasing physical activity in children. The relevance of the issue is confirmed mainly by the global trend of declining physical activity and quality of movement, which is influenced by several factors. The main initiating reasons for conducting the study of children's activity are the impact on health and quality of life. The main areas of interest are importance of physical activity, beginning of physical activity, its frequency and subsequent development, including influencing factors during adolescence.

\section{THEORETICAL BACKGROUND}

Research clearly shows that adequate fitness and physical activity results in significant health benefits for individuals as well as significant socio-economic benefits for society as a whole. Examples of health benefits may be reduced risk or at least delayed onset of civilization diseases, such as childhood obesity or a proven positive effect of activity (and physical activity automatically leads to psychological) on delaying and possibly alleviating the onset of dementia at senior age (Care, 2019; Findholt, 2007; Guthold, Cowan, Autenrieth, Kann, \& Riley, 2010; Khan et al., 2009; Rolland, van Kan, \& Vellas, 2008; Verghese et al., 2003).

According to the study (Telama et al., 2005), it was concluded that a high level of physical activity at the age of 9 to 18 years, especially in the case of its continuity, significantly correlates with a high level of activity in adulthood. Simultaneously, another study (Dumith, Gigante, Domingues, \& Kohl III, 2011), summarizing facts from a adequate 26 studies, evaluated physical activity using a questionnaire and found a decrease during adolescence by an average of $7.0 \%$ per year.

The worldwide trend of insufficient activity of adolescents (11 to 17 years) implies the need to address this situation. A study (Guthold, Stevens, Riley, \& Bull, 2020) conducted by WHO researchers showed that more than $80 \%$ of adolescents worldwide did not follow the recommendation of at least one hour of physical activity per day (Gába, 2018; Martins, Marques, Sarmento, \& Carreiro da Costa, 2015). Several studies from different years (Downward \& Rasciute, 2015; Draper, Basset, De Villiers, \& Lambert, 2014; Sherar, Esliger, Baxter-Jones, \& Tremblay, 2007; Trost et al., 2002) (Care, 2019) point to the fact that boys are more physically active than girls in all ages at all ages. Guthold et al report prevalence of insufficient physical activity in boys $78 \%$ and in girls $85 \%$. In connection with gender, on the basis of this study, numbering 1.6 million probands, students from all 146 countries, girls can be identified as less active compared to boys (Guthold et al., 2020).

Ending a sports career is a highly discussed topic, especially in relation to the elite sphere. The literature (Alfermann, Stambulova, \& Zemaityte, 2004; Jansa, 2017) in relation to the end of a (professional) sports career introduces a basic division into involuntary (forced by circumstances) and voluntary termination (free choice).

Most authors are particularly concerned with elite athletes (Arvinen-Barrow, DeGrave, Pack, \& Hemmings, 2019; Fernandez, Stephan, \& Fouquereau, 2006; Knights, Sherry, Ruddock-Hudson, \& O'Halloran, 2019; Moesch, Mayer, \& Elbe, 2012). However, some research has also searched for motives in amateur-level athletes 
(Ristolainen, Kettunen, Kujala, \& Heinonen, 2012). In most cases, the available literature agrees on the multifactoriality of the reasons, ie the interplay of circumstances.

Among the psychological factors, there are specifically reasons such as: lack of or, conversely, excessive motivation, dissatisfaction or frustration due to failure to achieve set goals, anxiety caused by excessive pressure. Examples of social factors include: loss of a sports partner, unsatisfactory environment or team, disagreements and bad relationships within the club or with teammates, other hobby activities, work or study workload, lack of time for the family, loss of family support (Crespo \& Miley, 2003; Moesch et al., 2012).

\section{OBJECTIVES OF THE WORK}

The aim of the work was to obtain and analyze data on the subject of the current state of physical activity of children from multi-year grammar schools in Prague, including the sports history of each proband. The work is focused on the history of the beginning of the child's involvement in the sport and its further development up to the present. The partial goal is to investigate the reasons for the termination of physical activities, as well as the reason for avoiding physical activities in a given sample of the population.

\section{METHODS}

The work is an empirical quantitative study. A one-off anonymous questionnaire survey was used to obtain data via an electronic form at selected multi-year grammar schools without specialized focus of study in Prague. The researched phenomenon is physical and particularly sports activity at the time of research, including the history of its development in specific individuals.

The research group consisted of children regardless of gender between the ages of 11 and 19 attending selected multi-year grammar schools in Prague, which, through management, agreed to the children's participation in the study. The reason for selecting this subpopulation is the homogeneity of the sample in terms of age and social classification and at the same time the personality spectrum of children. The number of individuals in the sample was limited by the number of these facilities in Prague and the willingness of school management to participate in the research. Subsequently, a responsible, non-participating person was contacted, who ensured the distribution of the form among students of specific classes.

\section{Data collection method}

The questionnaire was created in the form of CAWI (Computer-Assisted Web Interviewing), ie online research including distribution and data collection. The environment for the form or the questionnaire was provided by the Google Docs service. The final form of the questionnaire contained a combination of question forms. The most frequent was the form of closed questions of alternative (selective) and enumerated type. Within several open questions, one can also be considered as control for previous answers.

Data collection took place in the period before and after the summer holidays of 2019. Most schools, or school management, used information technology lessons to complete the questionnaire. Other schools sent a link to the questionnaire directly 
to the students using school e-mail addresses, and educators orally introduced them to the essence of the research. After the collection, the data were converted to a table in csv format for further analysis.

\section{Factors of termination of physical activity (PA)}

For the purposes of this work, the division of reasons into main groups (factors) was created on the basis of answers. Psychosocial factors (Cumps, Verhagen, \& Meeusen) included responses such as a psychological block based on an event within the collective or the collective as such, moving, but also loss of interest and motivation. Health factors $(\mathrm{H})$ included all the answers on the topic of long-term illness, injury or injury limiting the comfortable continuation of PA. Training factors (T) included the options of the coach leaving, high demands on the respondent, the breakdown of the club, category or association, as well as capacity issues.

\section{Data processing}

The total number of completed questionnaires $(\mathrm{n}=566)$ was checked and any incorrectly completed questionnaires were removed and excluded from further analysis. The control of the data thus consisted in the assessment of the factual content, the authenticity of the answers and the elimination of meaninglessly filled in forms (especially open-ended questions).

\section{Data analysis}

As part of quantitative research, the analysis of descriptive statistics was carried out in two phases. The classification of the first stage took place mainly using the MS Excel environment, including output tables and graphs, or the calculation of mean values. The GraphPad Prism 8 system and the R mathematical system were used for the statistical analysis of the second stage, including graphical representation.

For all second-stage analyses, descriptive statistics and normality tests (Shapir-Wilk, Kolmogorov-Smirnov, and QQ plots) were first calculated for the data to test whether the values were from the normal probability distribution. Based on the result, a choice was subsequently made between tests for parametric or non-parametric data distribution for hypothesis testing.
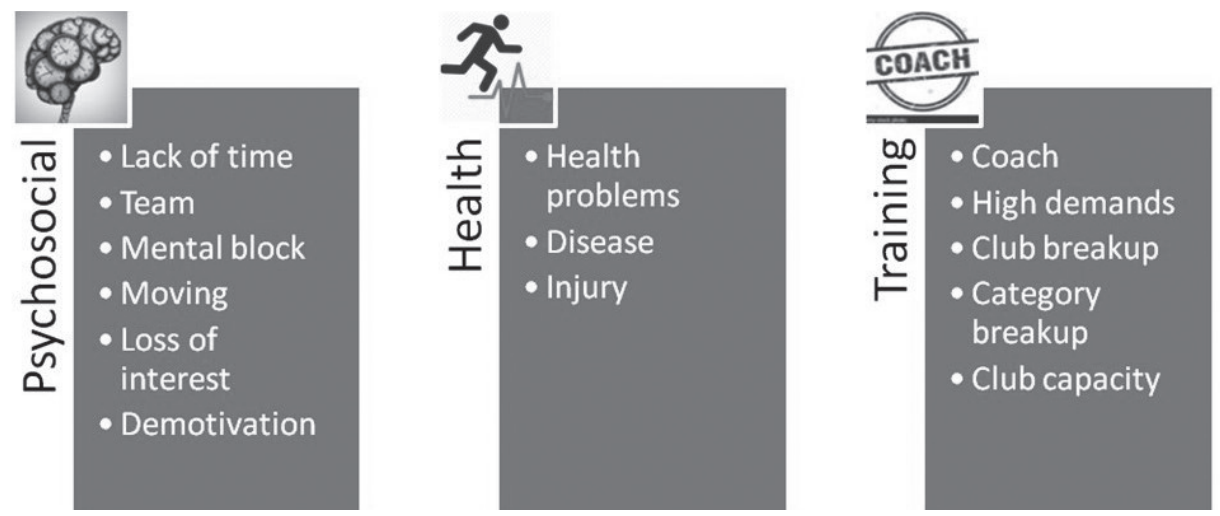

Table 1 Categorization of termination factors of PA adolescents according to survey answers 


\section{Correlation analysis}

For all examined dependencies, Spearman's test was used for correlation analysis due to non-parametric distribution of data (normality tests had a negative result). The significance level was maintained at its standard value of $\alpha=0.05(5 \%)$ and had a two-sided p-value variant for all analyses.

\section{Comparison of two selections}

To test one of the established hypotheses, a comparison of two sets was used, namely boys and girls and their volume of physical activity per week. Due to the repeated negative result of the normality tests, the Wilcoxon two-sample test (Mann-Whitney) was used. For this analysis, the level was also set at $\alpha=0.05$ (5\%) with a variant of the two-sided p-value.

\section{RESULTS}

\section{File characteristics}

After excluding incomplete questionnaires, the girls represented a majority $(\mathrm{n}=328$; $58 \%$ ) compared to boys $(\mathrm{n}=235 ; 42 \%)$. From the graphic visualization, this ratio is visible in all age groups except at 13 years, where there is a higher proportion of boys. The age distribution of respondents shows a higher proportion of high school children at age 15 years $(n=134 ; 23.8 \%)$ and 16 years $(n=120 ; 21.3 \%)$. On the contrary, the extreme groups reached a markedly low proportion, 11 years $(\mathrm{n}=12 ; 2.1 \%)$ and 19 years $(\mathrm{n}=10 ; 1.7 \%)$.

\section{Types of sports}

The total sum of answers significantly exceeds the number of respondents due to the possibility to choose more physical activities. The possible choice of sports was dominated by swimming $(\mathrm{n}=261 ; 50.2 \%)$ and martial arts $(\mathrm{n}=131 ; 25.2 \%)$. Among

$$
\text { - Boys (235) Girls (328) }
$$

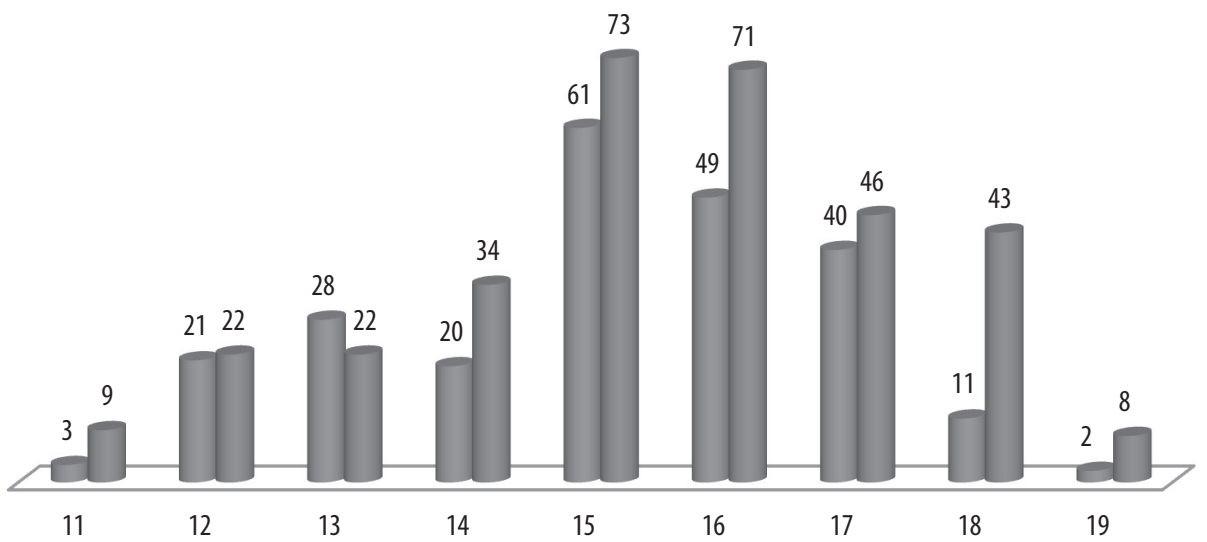

Graph 1 Overview of the number of girls and boys by age in the examined sample $(n=563)$ 
girls, dance was also frequent $(\mathrm{n}=71 ; 23.9 \%)$. Less common sports include tennis (59; $11.3 \%)$, athletics $(58 ; 11.2 \%)$, girls' volleyball $(\mathrm{n}=43 ; 14.5 \%)$ and boys' floorball $(n=43) .37 ; 16.6 \%)$. A slight surprise is the result of football $(n=38 ; 7.3 \%)$, which is numerically only slightly above the mean value $(\mathrm{Me}=29)$.

Despite the effort to include all of the most probable types of sports activities, it was obviously not possible and the group "Other" was the most frequently selected $(\mathrm{n}=332 ; 63.8 \%)$.

Table 2 Detailed frequency of sports

\begin{tabular}{|c|c|c|c|c|c|c|}
\hline Sport (type) & Boys (223) & $\%$ & Girls (297) & $\%$ & Overall (520) & $\%$ \\
\hline American football & 1 & 0.4 & 0 & 0.0 & 1 & 0.2 \\
\hline Athletics & 23 & 10.3 & 35 & 11.8 & 58 & 11.2 \\
\hline Badminton & 11 & 4.9 & 10 & 3.4 & 21 & 4.0 \\
\hline Baseball & 10 & 4.5 & 2 & 0.7 & 12 & 2.3 \\
\hline Basketball & 22 & 9.9 & 9 & 3.0 & 31 & 6.0 \\
\hline Martial arts & 80 & 35.9 & 51 & 17.2 & 131 & 25.2 \\
\hline Cycling & 22 & 9.9 & 13 & 4.4 & 35 & 6.7 \\
\hline Floorball & 37 & 16.6 & 12 & 4.0 & 49 & 9.4 \\
\hline Football (soccer) & 34 & 15.2 & 4 & 1.3 & 38 & 7.3 \\
\hline Golf & 3 & 1.3 & 1 & 0.3 & 4 & 0.8 \\
\hline Gymnastics & 8 & 3.6 & 20 & 6.7 & 28 & 5.4 \\
\hline Ice hokey & 3 & 1.3 & 0 & 0.0 & 3 & 0.6 \\
\hline Lacross & 4 & 1.8 & 2 & 0.7 & 6 & 1.2 \\
\hline Climbing, Boulder & 15 & 6.7 & 15 & 5.1 & 30 & 5.8 \\
\hline Skiing & 22 & 9.9 & 14 & 4.7 & 36 & 6.9 \\
\hline Swimming & 104 & 46.6 & 157 & 52.9 & 261 & 50.2 \\
\hline Parkour & 8 & 3.6 & 2 & 0.7 & 10 & 1.9 \\
\hline Showjumping, Horse racing & 1 & 0.4 & 15 & 5.1 & 16 & 3.1 \\
\hline Rugby & 2 & 0.9 & 0 & 0.0 & 2 & 0.4 \\
\hline Softball & 4 & 1.8 & 5 & 1.7 & 9 & 1.7 \\
\hline Table tennis & 15 & 6.7 & 4 & 1.3 & 19 & 3.7 \\
\hline Dancing (ballet) & 9 & 4.0 & 71 & 23.9 & 80 & 15.4 \\
\hline Tennis & 27 & 12.1 & 32 & 10.8 & 59 & 11.3 \\
\hline Rowing & 6 & 2.7 & 4 & 1.3 & 10 & 1.9 \\
\hline Volleyball & 9 & 4.0 & 43 & 14.5 & 52 & 10.0 \\
\hline Other & 123 & 55.2 & 209 & 70.4 & 332 & 63.8 \\
\hline
\end{tabular}

\section{Frequency and volume of physical activities}

The visible conditional formatting of the table data, including additional fattening, shows that more than half of the interviewed children play sports with a frequency of two to four trainings sessions per week $(\mathrm{n}=318 ; 61.2 \%)$. About a third of children complete more than 5 trainings $(\mathrm{n}=137 ; 26.3 \%)$. 
Table 3 Frequency of physical activities in the weekly regime

\begin{tabular}{l|c|c|c}
\hline Frequency per week & Boys (223) & Girls (297) & Overall (520) \\
\hline Once & 26 & 39 & 65 \\
\hline Twice & 35 & 60 & $\mathbf{9 5}$ \\
\hline Three times & 63 & 68 & $\mathbf{1 3 1}$ \\
\hline Four times & 33 & 59 & $\mathbf{9 2}$ \\
\hline Five times & 26 & 30 & 56 \\
\hline Six times & 26 & 23 & 49 \\
\hline Seven times & 14 & 18 & 32 \\
\hline Median (Me) & $\mathbf{2 6}$ & $\mathbf{3 9}$ & $\mathbf{6 5}$ \\
\hline
\end{tabular}

In case of the total amount of time devoted to sports, including competitions, 3 to 6 hours per week represent almost a half of the average values $(n=229 ; 44 \%)$. However, a significant number of children answered that they spend 7 to 8 hours a week playing sports $(n=76 ; 14.6 \%)$ and the same amount even up to 12 hours $(n=76 ; 14.6 \%)$.

Table 4 Hourly volume of physical activities in the weekly mode

\begin{tabular}{l|c|c|c}
\hline Volume per week (hours) & Boys (223) & Girls (297) & Overall (520) \\
\hline 1 to 2 & 34 & 50 & 84 \\
\hline $\mathbf{3}$ to 4 & 50 & 65 & $\mathbf{1 1 5}$ \\
\hline $\mathbf{5}$ to 6 & 50 & 64 & $\mathbf{1 1 4}$ \\
\hline 7 to 8 & 28 & 48 & 76 \\
\hline 9 to 10 & 27 & 28 & 55 \\
\hline 11 to 12 & 34 & 42 & 76 \\
\hline Median (Me) & $\mathbf{3 4}$ & $\mathbf{4 9}$ & $\mathbf{8 0}$ \\
\hline
\end{tabular}

\section{Muculoskeletal disorder as a limitation of sport}

All respondents were asked about the musculoskeletal disorders associated with sports, possibly in recreational form. The answers were evenly distributed, only the answer "No", ie no experience with difficulties in sports was slightly more frequent $(\mathrm{n}=219 ; 38.9 \%)$. Girls $(\mathrm{n}=104 ; 31.7 \%)$ reported slightly more frequent difficulties (pain) than boys ( $\mathrm{n}=62 ; 26.4 \%)$.

Table 5 Number and percentage representation of the frequency of difficulties of the examined sample of individual body sites ONLY TABLE

\begin{tabular}{l|c|c|c|c|c|c}
\hline Body part & Boys (140) & \% & Girls (204) & $\%$ & Overall (344) & $\%$ \\
\hline Head & 7 & 5.0 & 9 & 4.4 & 16 & 4.7 \\
\hline Neck & 2 & 1.4 & 6 & 2.9 & 8 & 2.3 \\
\hline Upper extremity & 31 & 22.1 & 41 & 20.1 & $\mathbf{7 2}$ & $\mathbf{2 0 . 9}$ \\
\hline Tors0 & 13 & 9.3 & 22 & 10.8 & 35 & 10.2 \\
\hline Knee & 43 & 30.7 & 65 & 31.9 & $\mathbf{1 0 8}$ & $\mathbf{3 1 . 4}$ \\
\hline Ankle & 44 & 31.4 & 61 & 29.9 & $\mathbf{1 0 5}$ & $\mathbf{3 0 . 5}$ \\
\hline
\end{tabular}


In the majority of cases it was a sport restriction of a temporary nature $(n=210$; $61.0 \%)$. Other options were relatively rare. Only in $15.7 \%(n=54)$ of cases there were no restrictions in sport. Restricted mobility occurred in boys in $20.0 \%(n=28)$. In contrast, in the case of girls, there was a relatively high percentage $(n=78 ; 38.2 \%)$ of recurrent pain.

Table 6 Impact of physical disorders encountered

\begin{tabular}{l|c|c|c|c|c|c}
\hline Restrictions due disorders & Boys (140) & \% & Girls (204) & \% & Overall (344) & $\%$ \\
\hline None & 25 & 17.9 & 29 & 14.2 & 54 & 15.7 \\
\hline Temporarily & $\mathbf{9 5}$ & $\mathbf{6 7 . 9}$ & $\mathbf{1 1 5}$ & $\mathbf{5 6 . 4}$ & $\mathbf{2 1 0}$ & $\mathbf{6 1 . 0}$ \\
\hline Permanent & 6 & 4.3 & 15 & 7.4 & 21 & 6.1 \\
\hline $\begin{array}{l}\text { Lasting significantly longer } \\
\text { than necessary for healing }\end{array}$ & 10 & 7.1 & 17 & 8.3 & 27 & 7.8 \\
\hline Performance decrease & 19 & 13.6 & 21 & 10.3 & 40 & 11.6 \\
\hline Mobility restriciton & 28 & 20.0 & 25 & 12.3 & 53 & 15.4 \\
\hline Recurrent pain & 22 & 15.7 & $\mathbf{7 8}$ & $\mathbf{3 8 . 2}$ & 100 & 29.1 \\
\hline
\end{tabular}

\section{Factors of reduced physical activity}

For the purposes of the investigation, the question on the subject was of an open type. Based on the answers and theoretical background, a categorization of factors (reasons) for the termination of PA was created. The summary of the survey results is presented in Table 16. Graph 8 shows the predominance of factors that were defined as psychosocial $(\mathrm{n}=70 ; 76.9 \%)$.

Table 7 List of reasons for termination of physical activity (own resource)

\begin{tabular}{l|c|c}
\hline PA termination reasons & Factor & 0verall (98) \\
\hline Lack of time (time-consuming) & PS & 31 \\
\hline Team & PS & 6 \\
\hline Loss of interest ("I didn't like it") & PS & 29 \\
\hline Coach (high demands) & T & 10 \\
\hline Health (illness, injury) & H & 14 \\
\hline Moving & PS & 3 \\
\hline Club/category breakup & T & 3 \\
\hline Mental block due the partner's injury & PS & 1 \\
\hline Club capacity & T & 1 \\
\hline Number of respondents & & 91 \\
\hline
\end{tabular}

Note: PS - psychosocial, $\mathrm{H}$ - health, $\mathrm{T}$ - training

\section{STATISTICAL ANALYSIS}

\section{Relationship between age and volume of physical activity}

In an effort to determine the connection between different ages and total weekly activity, a correlation analysis was performed. For a set of 520 participants aged 11 to 19 years, the median value was calculated to $\mathrm{Me}=5.5$. In the retroactive conversion 


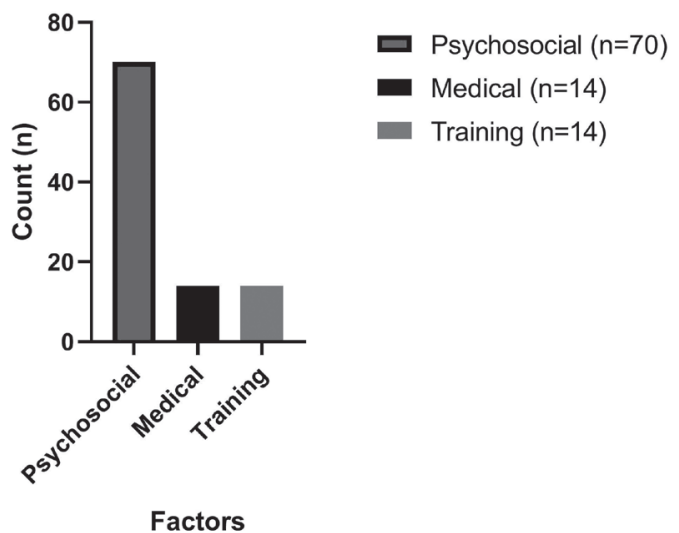

Graph 2 Representation of categorized reasons for termination of PA in adolescents (medical reason = health category)

from nominal value, the median corresponds to the option " 5 to 6 hours". The graph below shows the linear regression curve. Although it has an increasing tendency $(\mathrm{r}=0.01)$, the $\mathrm{p}$ value $(\mathrm{p}=0.80)$ is insignificant with respect to the determined level of $\alpha(0.05)$. And the assumption that the volume of physical activity will decrease in older age has not been confirmed, it even has the opposite tendency.

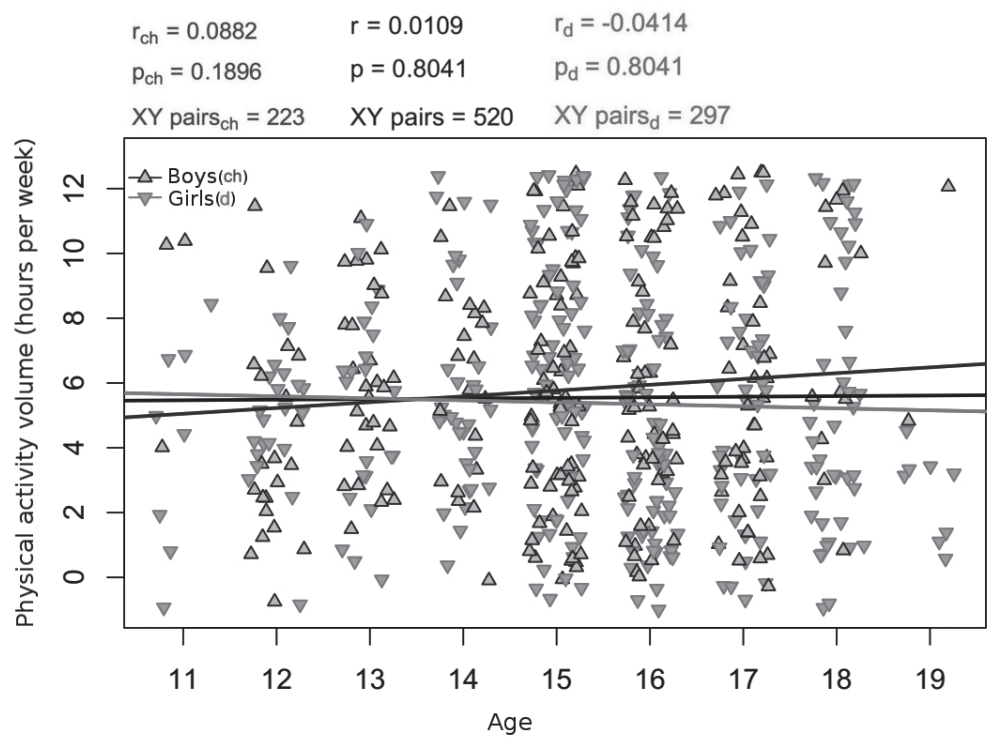

Graph 3 Dependence of the volume of physical activity on the age of respondents, including the difference by gender; linear regression

\section{Relationship between age and frequency of physical activity}

Similarly, to study the correlation between age and frequency of PA, the analysis was performed first in the original age range. The investigated dependence of the frequency of physical activities on age has already been found to be statistically significant at the level $\boldsymbol{\alpha}=0.05(\mathrm{p}=0.02)$, confirming the higher frequency of PA with increasing age. 


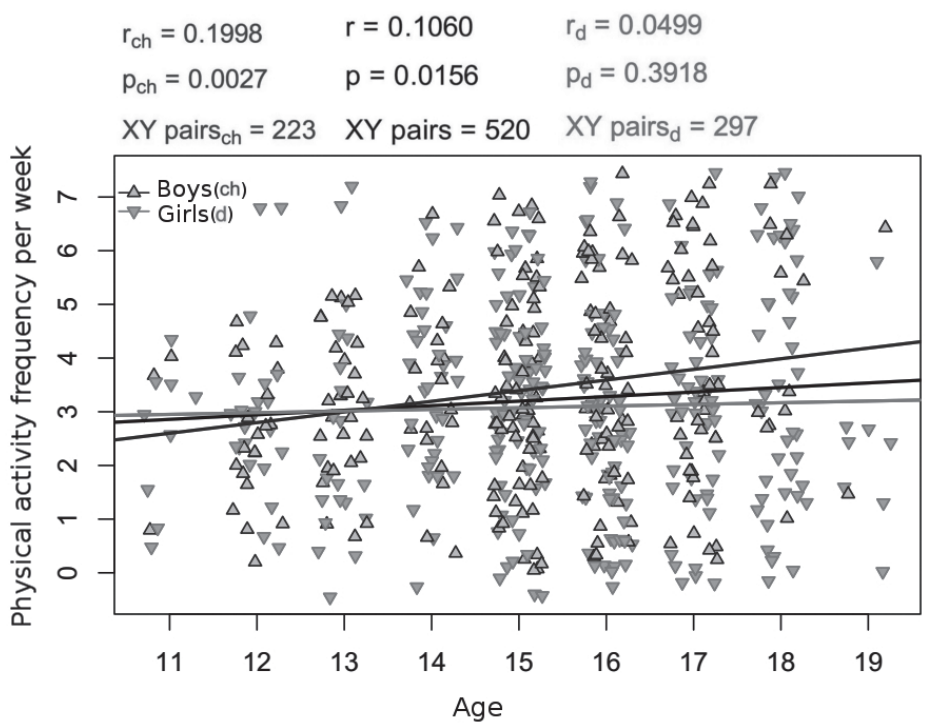

Graph 4 Dependence of the frequency of physical activity on the age of respondents, including the difference by gender; linear regression

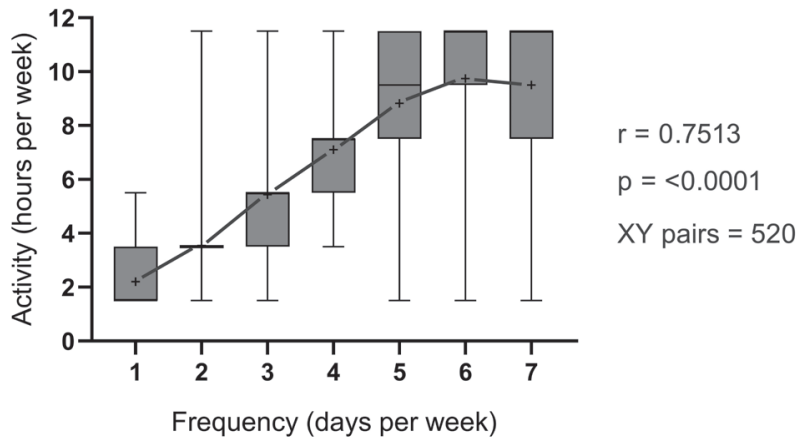

Graph 5 Dependence of the frequency of physical activity on the volume of activity

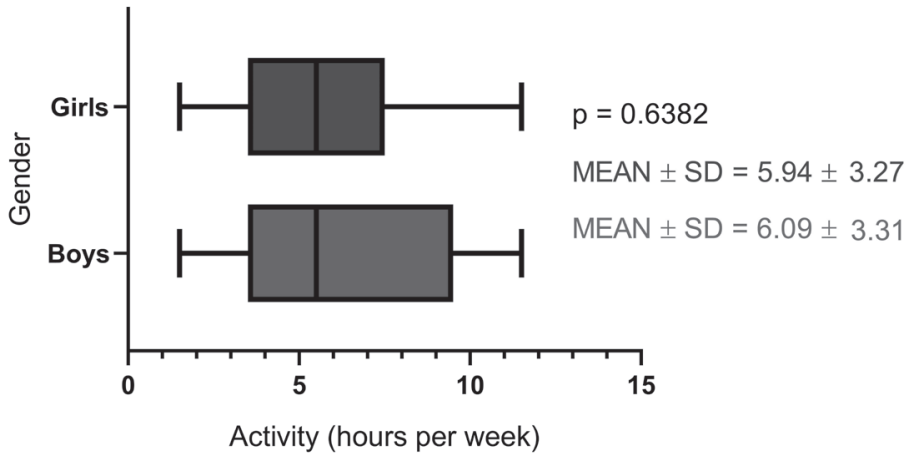

Graph 6 Average volume of physical activity in girls and boys 


\section{Gender and volume of sports activity}

Comparison of the two groups by non-parametric test shows the expected tendency of higher physical activity of boys compared to girls, but with insufficient value of significance $(\mathrm{p}=0.64)$ at the determined level of $a(0.05)$. On the box graph (reference to the graph) it is possible to see identical median values, but a different $75 \%$ percentile, which is equal to 7.5 ("7 to 8 hours") in girls, 9.5 ("9 to 10 hours") in boys.

\section{DISCUSSION}

In the group of students from multi-year grammar schools in Prague, the value of the correlation coefficient was positive, so with increasing age there is a tendency for the time spent on physical activity to increase. However, in relation to the question on the total number of hours of physical activity per week, insufficient value was reached for statistical significance.

With the same tendency but with sufficient p-value (significance) in this research, it turned out that a specific population of children plays sports more often as they age. However, it cannot be said with certainty that they spend more time during the week on physical activities.

Globally, several longitudinal, cross-sectional, and other studies recognize that there is a significant decrease in activity during adolescence (Collings et al., 2015; Dumith et al., 2011; Martins et al., 2015; Murray, Calderwood, O'Connor, \& Mutrie, 2016; Reilly, 2016). This fact was recorded as early as 1998, when Gavarry et al. confirmed this tendency in moderately intensive activity (Gavarry et al., 1997). The 2003 study reached the same result in the Moderate to Vigorous Physical Activities MVPA relationship (Mota, Santos, Guerra, Ribeiro, \& Duarte, 2003). The linear course of decrease in PA (from 9 to 17 years of age) and the specific breakpoint (14 years) were described by Wall et al. with the subsequent largest decline in PA in both genders (Wall, Carlson, Stein, Lee, \& Fulton, 2011).

However, in recent history, there have also been studies that have not found an evident decrease in the physical activity of adolescents (Harding, Page, Falconer, \& Cooper, 2015; Mitchell et al., 2012). In their conclusions Harding et al. only confirmed the increased value of time spent in a sedentary manner. Another study confirmed a decrease in activity, but only of a mild nature, especially in the case of boys (Corder et al., 2015).

Research in the Czech Republic, Rubín points to the equally surprising result of the increase in physical activity with increasing age (Rubín et al., 2018). However, this is a research on the population of adolescents with the MVPA measurement. However, the author points out the generally declining trend of the common physical activity (for example, taken steps) in the population of Czech adolescents since 1998.

Despite the fact that Rubín studied MVPA on a common sample of the adolescent population, the study took place in the context of an artificially built environment (Rubín et al., 2018). These were larger cities, with the exception of Prague, but the trend in the results still coincides with our results.

The original assumption was that with the increasing complexity of teaching, the amount of time devoted to physical activities will decrease. It can be assumed that with older age the frequency of PA increases, for example due to more frequent match- 
es or racing activities (Way, 2019). The results of this work could also be explained by a general increase in the complexity of training plans in most sports based on the physiological development of the child's body. According to the LTPD recommendations, in the case of training a hockey player from the age of 12 to the age of 18 , increases the time on ice during training and the number of matches increases by up to half (Wall et al., 2011). In the case of swimming, by the age of 12 years, the recommended time spent in the pool doubles (American Swimming, 2017; Radford, 2008). In the next period, up to about 18 years of age, however, the volume is maintained and there is more focus on specialization and periodization.

The disadvantage of the questionnaire survey with regard to the conclusion of not only this hypothesis could be the insufficient understanding of the term "performance sport" by students. It is not possible to trace back which of the respondents is a performance athlete and which is only a recreational one. Thus, there is no differentiation of the level of PA in individual respondents. The question is to what extent this difference affects the results. Just in the sense that we expect regular, intensive training for performance athletes. For recreational athletes, it may be a lower intensity and even an irregular PA.

Another result was the confirmation that the most common reason for the reduction or termination of dominant sports and physical activity is psychosocial factors. Respondents in the questionnaire survey listed the reasons for which they ended the sport. It was an open question.

The most common factor was psychosocial reasons in terms of lack of time and, in general, the time required for physical activity and its effect on school workload. The very next reason was the loss of interest, especially the lack of fun and the lack of a sense of fulfillment from the activity. Only half of the responses stated the reason for no longer participating in PA as an injury or illness. Ultimately, we can interpret these answers as the fulfillment of both parts of the term "psychosocial".

The categorization of factors itself is not entirely unambiguous, because according to the cited literature, the reasons for the termination of sports activities are very often multifactorial.

Several studies (Azzarito \& Hill, 2013; Knowles, Niven, \& Fawkner, 2011; Slater \& Tiggemann, 2010) state that adolescents do not value competitive-type physical activities (exposing them to competition) and, paradoxically, for them, the performance-motivating climate is a barrier to further sports activities. Adverse factors included adolescent pressure for victory, failure in front of peers, and negative peer reactions; feeling discomfort or lack of fun. One factor was also the lack of study opportunities (Martins et al., 2015; Quaresma, Palmeira, Martins, Minderico, \& Sardinha, 2015). Even in our investigation, there were reasons such as high demands of coaches or the team. A very common reason given by girls in particular $(60 \%)$ in the research of Kimm et al. is the lack of time for PA (Kimm et al., 2006). Another reason was fatigue and lack of interest in activity.

Although some studies Quaresma et al. mention the considerable importance of the influence of the family, especially parents, none of the respondents answered in this sense (Quaresma et al., 2015). For children who have avoided PA all their lives, the role of parents could play a role in not leading the child to physical activities. The possibility of limited funding, i.e., socio-economic status (SES), concerned only one 
respondent. However, according to the results of the study (Martins et al., 2015), it was found that lower SES leads to a demonstrably lower incidence of MVPA during the day.

The higher sports activity at older school age of boys compared to girls is pointed out by many authors of various studies. It is possible to consider the same tendency in the case of this research, but in this case the value ensuring the significance of the result was not achieved. Globally, there is a decline in activity during adolescence, which is more pronounced in girls than in boys (Barnett, Ridgers, \& Salmon, 2015; Bringolf-Isler et al., 2015; Brodersen, Steptoe, Boniface, \& Wardle, 2007; Collings et al., 2015; Metcalf, Hosking, Jeffery, Henley, \& Wilkin, 2015; Reilly, 2016). Martins et al. speak of higher evidence in the case of older adolescents boys (Martins et al., 2015).

However, four other studies (Corder et al., 2015; Harding et al., 2015; Mitchell et al., 2012) do not support the general view that the decrease in PA during adolescence is more pronounced in girls than in boys. Even in an older study by Gavarry et al. did not find a gender difference in different intensities of PA (Gavarry et al., 1997). In contrast, Collings et al. found a slightly higher decrease in boys than in girls (Collings et al., 2015).

The study of Rubín (Rubín et al., 2018) did not confirm significantly higher or otherwise different physical activity in Czech adolescent boys compared to girls. On the contrary, the results of a significant difference in PA in favor of boys were obtained by the Czech authors (Frömel, Novosad, \& Svozil, 1999). The girls lagged behind in both intensity and volume of activity (Neuls \& Frömel, 2016).

Very interesting results are summarized in the publication of Rychetský and Tilinger, where they compare participation in PA by gender using COMPASS methodologies from 1998 to 2015. In general, the difference in activity by gender was confirmed in terms of higher decline in girls, especially in the form of unorganized sport and PA. The authors summarize the facts into a general statement that boys are more involved in intense, organized activities than girls, who prefer unorganized PAs of lower intensity and frequency (Rychtecký \& Tilinger, 2018).

Inconsistent results point to the complexity of defining a clear conclusion. The results are probably strongly influenced by a specific population sample. The issue of comparing studies is not only the possible implementation of different ethnicities, performance groups, but of course also different approaches to data acquisition. In general, questionnaires are often used in this field. However, these are slightly criticized for possible data bias. Pedometers seem to be more reliable, but they only provide data on the number of steps. Accelerometers appear to be the most suitable form. Larger studies use a combination of at least two measurement methods.

A slight indication of the difference between the activity of boys and girls also appeared in this study. This would be in line with the conclusions of the above-mentioned research by Rychetský and Tilinger, i.e. that boys prefer more intensive and organized forms of activities. This should theoretically explain slightly higher numbers in boys, both in terms of frequency and total PA volume (Rychtecký \& Tilinger, 2018). However, the difference is not significant, as girls are not literally less active, but only select activities of lower intensity. We can also consider the higher responsibility of girls in their studies, or the effort for a better benefit compared to the common approach of the majority of boys. 
While the level of fundamental motor skills (FMS) is demonstrably associated with the current level of PA and fitness of both younger school-age children and adolescents (Capio, Sit, Eguia, Abernethy, \& Masters, 2015; Jaakkola \& Washington, 2013; Lai et al., 2014; Morgan et al., 2013), the question is whether this is also the case in terms of future activity levels.

As a result, most studies on this issue repeatedly mention the importance of completing the "active start" phase providing early childhood (up to 6 years of age) training in FMS (skills). Barnett et al. even state motor competence in childhood as a predictor of activity in adolescence, however only evaluated by respondents independently (Barnett et al., 2015). The above-cited study indicates a significant relationship between physical training, i.e. obtaining a sufficient level of FMS and the activity of children and adolescents. However, it is assumed that activity levels and motor skills may be affected by other factors such as self-perception, socioeconomic status, and family attitude toward PA (Barnett et al., 2015; Freitas, Gabbard, Caçola, Montebelo, \& Santos, 2013; McGrane, Belton, Powell, \& Issartel, 2017).

\section{LIMITATIONS}

The representation of respondents of individual age categories is strongly influenced by the approach of school management to filling in the questionnaire form. It is obvious that, especially for marginal age groups, the form was distributed only via school e-mail.

\section{CONCLUSION}

Due to the global lack of exercise in addition to the prevalent sedentary lifestyle, there is a lot of research and studies mapping the issue. The positive result of this study is that the trend of decrease in the volume of physical activity with increasing age of the child was not confirmed. On the contrary, the results suggest that with increasing age, the frequency of physical activities in the studied population increases. This cannot be stated unequivocally in the case of girls in whom the increase in frequency does not reach the level of significance. For the total volume of activities, however, the results did not confirm a significantly higher activity in boys compared to girls. The significant dependence of physical activity on the completion of physical training was also not confirmed. Conformity with general findings, on the other hand, was found in the localization of the most frequent problems (pain, injury), which turned out to be predominantly in the lower limbs (esp. knee and ankle). However, psychosocial factors most often led adolescents to reduce or stop physical activity.

We see the importance of the results of the work mainly in the specification of the current situation of physical activity in the selection of the adolescent population. In a given sample of the population with increasing age, there is no significant reduction in the volume of physical activity. Support for activity therefore seems appropriate and beneficial for individuals who, for psychosocial reasons, leave the activity completely. In some cases, the solution could be offering the possibility to simply change the type of activity or level of performance to relieve pressure on individuals. 


\section{REFERENCES}

Alfermann, D., Stambulova, N., \& Zemaityte, A. (2004). Reactions to sport career termination: a cross-national comparison of German, Lithuanian, and Russian athletes. Psychology of Sport and Exercise, 5(1), 61-75.

American development model for swimming. USA Swimming [online]. Colorado Springs: USA Swimming, 2012, Retrieved [June, 2020] from https://www.usaswimming.org/docs /default-source/coaching-resourcesdocuments/american-development-model-for -swimming.pdf.

Arvinen-Barrow, M., DeGrave, K., Pack, S., \& Hemmings, B. (2019). Transitioning Out of Professional Sport: The Psychosocial Impact of Career-Ending Non-Musculoskeletal Injuries Among Male Cricketers From England and Wales. Journal of Clinical Sport Psychology, 13(4), 629-644.

Azzarito, L., \& Hill, J. (2013). Girls looking for a 'second home': Bodies, difference and places of inclusion. Physical Education and Sport Pedagogy, 18(4), 351-375.

Barnett, L. M., Ridgers, N. D., \& Salmon, J. (2015). Associations between young children's perceived and actual ball skill competence and physical activity. Journal of Science and Medicine in Sport, 18(2), 167-171.

Bringolf-Isler, B., Mäder, U., Dössegger, A., Hofmann, H., Puder, J. J., Braun-Fahrländer, C., \& Kriemler, S. (2015). Regional differences of physical activity and sedentary behaviour in Swiss children are not explained by socio-demographics or the built environment. International Journal of Public Health, 60(3), 291-300.

Brodersen, N. H., Steptoe, A., Boniface, D. R., \& Wardle, J. (2007). Trends in physical activity and sedentary behaviour in adolescence: ethnic and socioeconomic differences. British Journal of Sports Medicine, 41(3), 140-144.

Capio, C. M., Sit, C. H., Eguia, K. F., Abernethy, B., \& Masters, R. S. (2015). Fundamental movement skills training to promote physical activity in children with and without disability: A pilot study. Journal of Sport and Health Science, 4(3), 235-243.

Collings, P. J., Wijndaele, K., Corder, K., Westgate, K., Ridgway, C. L., Sharp, S. J., . . Brage, S. (2015). Magnitude and determinants of change in objectively-measured physical activity, sedentary time and sleep duration from ages 15 to $17.5 \mathrm{y}$ in UK adolescents: the ROOTS study. International Journal of Behavioral Nutrition and Physical Activity, 12(1), 1-10.

Corder, K., Sharp, S. J., Atkin, A. J., Griffin, S. J., Jones, A. P., Ekelund, U., \& van Sluijs, E. M. (2015). Change in objectively measured physical activity during the transition to adolescence. British Journal of Sports Medicine, 49(11), 730-736.

Crespo, M., \& Miley, D. (2003). Tenisový trenérský manuál 2. stupně: pro vrcholové trenéry. Olomouc: Univerzita Palackého.

Cumps, E., Verhagen, E., \& Meeusen, R. (2007). Prospective epidemiological study of basketball injuries during one competitive season: ankle sprains and overuse knee injuries. Journal of Sports Science \& Medicine, 6(2), 204-211.

DHSC - Department of Health \& Social Care (2019). UK Chief Medical Officers' Physical Activity Guidelines. Retrieved [June, 2020] from https://assets.publishing.service.gov.uk /government/uploads/system/uploads/attachment_data/file/832868/uk-chief-medical -officers-physical-activity-guidelines.pdf.

Downward, P., \& Rasciute, S. (2015). Exploring the covariates of sport participation for health: an analysis of males and females in England. Journal of Sports Sciences, 33(1), 67-76.

Draper, C., Basset, S., De Villiers, A., \& Lambert, E. V. (2014). Results from South Africa's 2014 report card on physical activity for children and youth. Journal of Physical Activity and Health, 11(s1), S98-S104.

Dumith, S. C., Gigante, D. P., Domingues, M. R., \& Kohl III, H. W. (2011). Physical activity change during adolescence: a systematic review and a pooled analysis. International Journal of Epidemiology, 40(3), 685-698. 
Fernandez, A., Stephan, Y., \& Fouquereau, E. (2006). Assessing reasons for sports career termination: Development of the Athletes' Retirement Decision Inventory (ARDI). Psychology of Sport and Exercise, 7(4), 407-421.

Findholt, N. (2007). Application of the community readiness model for childhood obesity prevention. Public Health Nursing, 24(6), 565-570.

Freitas, T. C., Gabbard, C., Caçola, P., Montebelo, M. I., \& Santos, D. C. (2013). Family socioeconomic status and the provision of motor affordances in the home. Brazilian journal of physical therapy, 17(4), 319-327.

Frömel, K., Novosad, J., \& Svozil, Z. (1999). Pohybová aktivita a sportovní zájmy mládeže. Olomouc: Univerzita Palackého.

Gába, A. e. a. (2018). Národní zpráva o pohybové aktivitě českých dětí a mládeže [online]. Retrieved [June, 2020] from https://www.activehealthykids.org/wp-content/uploads/2018/11/czech-republic-report-card-long-form-2018.pdf.

Gavarry, O., Bernard, T., Giacomoni, M., Seymat, M., Euzet, J., \& Falgairette, G. (1997). Continuous heart rate monitoring over 1 week in teenagers aged 11-16 years. European Journal of Applied Physiology and Occupational Physiology, 77(1-2), 125-132.

Guthold, R., Cowan, M. J., Autenrieth, C. S., Kann, L., \& Riley, L. M. (2010). Physical activity and sedentary behavior among schoolchildren: a 34-country comparison. The Journal of pediatrics, 157(1), 43-49, e41.

Guthold, R., Stevens, G. A., Riley, L. M., \& Bull, F. C. (2020). Global trends in insufficient physical activity among adolescents: a pooled analysis of 298 population-based surveys with 1.6 million participants. The Lancet Child \& Adolescent Health, 4(1), 23-35.

Harding, S. K., Page, A. S., Falconer, C., \& Cooper, A. R. (2015). Longitudinal changes in sedentary time and physical activity during adolescence. International Journal of Behavioral Nutrition and Physical Activity, 12(1), 44.

Jaakkola, T., \& Washington, T. (2013). The relationship between fundamental movement skills and self-reported physical activity during Finnish junior high school. Physical Education and Sport Pedagogy, 18(5), 492-505.

Jansa, P. (2017). Comparation attitudes and opinions of the adolescents at the age of 15-18 to the sport and movement activities. Studia sportiva, 11(1), 90-99.

Khan, L. K., Sobush, K., Keener, D., Goodman, K., Lowry, A., Kakietek, J., \& Zaro, S. (2009). Recommended community strategies and measurements to prevent obesity in the United States. Morbidity and Mortality Weekly Report: Recommendations and Reports, 58(7), 1-29.

Kimm, S. Y., Glynn, N. W., McMahon, R. P., Voorhees, C. C., Striegel-Moore, R. H., \& Daniels, S. R. (2006). Self-perceived barriers to activity participation among sedentary adolescent girls. Medicine and Science in Sports and Exercise, 38(3), 534-540.

Knights, S., Sherry, E., Ruddock-Hudson, M., \& O’Halloran, P. (2019). The End of a Professional Sport Career: Ensuring a Positive Transition. Journal of Sport Management, 33(6), 518-529.

Knowles, A.-M., Niven, A., \& Fawkner, S. (2011). A qualitative examination of factors related to the decrease in physical activity behavior in adolescent girls during the transition from primary to secondary school. Journal of physical activity and health, 8(8), 1084-1091.

Lai, S. K., Costigan, S. A., Morgan, P. J., Lubans, D. R., Stodden, D. F., Salmon, J., \& Barnett, L. M. (2014). Do school-based interventions focusing on physical activity, fitness, or fundamental movement skill competency produce a sustained impact in these outcomes in children and adolescents? A systematic review of follow-up studies. Sports Medicine, 44(1), 67-79.

Martins, J., Marques, A., Sarmento, H., \& Carreiro da Costa, F. (2015). Adolescents' perspectives on the barriers and facilitators of physical activity: a systematic review of qualitative studies. Health Education Research, 30(5), 742-755.

McGrane, B., Belton, S., Powell, D., \& Issartel, J. (2017). The relationship between fundamental movement skill proficiency and physical self-confidence among adolescents. Journal of Sports Sciences, 35(17), 1709-1714. 
Metcalf, B. S., Hosking, J., Jeffery, A. N., Henley, W. E., \& Wilkin, T. (2015). Exploring the adolescent fall in physical activity: a 10-yr cohort study (EarlyBird 41). Med. Sci. Sports Exerc., 47(10), 2084-2092.

Mitchell, J. A., Pate, R. R., Dowda, M., Mattocks, C., Riddoch, C., Ness, A. R., \& Blair, S. N. (2012). A prospective study of sedentary behavior in a large cohort of youth. Medicine and Science in Sports and Exercise, 44(6), 1081-1087.

Moesch, K., Mayer, C., \& Elbe, A.-M. (2012). Reasons for Career Termination in Danish Elite Athletes: Investigating Gender Differences and the Time-point as Potential Correlates. Sport Science Review, 21, 49-68.

Morgan, P. J., Barnett, L. M., Cliff, D. P., Okely, A. D., Scott, H. A., Cohen, K. E., \& Lubans, D. R. (2013). Fundamental movement skill interventions in youth: a systematic review and meta-analysis. Pediatrics, 132(5), e1361-e1383.

Mota, J., Santos, M., Guerra, S., Ribeiro, J., \& Duarte, J. A. (2003). Patterns of daily physical activity during days in children and adolescents. American Journal of Human Biology, 15(4), 547-553.

Murray, A., Calderwood, C., O'Connor, N., \& Mutrie, N. (2016). Scotland's progress in putting policy about physical activity into practice. Journal of the British Association of Sport and Exercise Medicine, 50(6), 320-321.

Neuls, F., \& Frömel, K. (2016). Pohybová aktivita a sportovní preference adolescentek. Olomouc: Univerzita Palackého.

Quaresma, A. M., Palmeira, A. L., Martins, S. S., Minderico, C. S., \& Sardinha, L. B. (2015). Psychosocial predictors of change in physical activity and quality of life in the PESSOA program: A school-based intervention study. Archives of Exercise in Health and Disease, 5(1-2), 366-376.

Reilly, J. J. (2016). When does it all go wrong? Longitudinal studies of changes in moderate-to-vigorous-intensity physical activity across childhood and adolescence. Journal of Exercise Science \& Fitness, 14(1), 1-6.

Ristolainen, L., Kettunen, J. A., Kujala, U. M., \& Heinonen, A. (2012). Sport injuries as the main cause of sport career termination among Finnish top-level athletes. European Journal of Sport Science, 12(3), 274-282.

Rolland, Y., van Kan, G. A., \& Vellas, B. (2008). Physical activity and Alzheimer's disease: from prevention to therapeutic perspectives. Journal of the American Medical Directors Association, 9(6), 390-405.

Rubín, L., Mitáš, J., Dygrýn, J., Vorlíček, M., Nykodým, J., Řepka, E., .. Valach, P. (2018). Pohybová aktivita a tělesná zdatnost českých adolescentů v kontextu zastavěného prostředí. Olomouc: Univerzita Palackého.

Rychtecký, A., \& Tilinger, P. (2018). Životni styl české mládeže. Pohybová aktivita, standardy a normy motorické výkonnosti. Praha: Karolinum.

Sherar, L. B., Esliger, D. W., Baxter-Jones, A. D., \& Tremblay, M. S. (2007). Age and gender differences in youth physical activity: does physical maturity matter? Medicine and Science in Sports and Exercise, 39(5), 830-835.

Slater, A., \& Tiggemann, M. (2010). "Uncool to do sport": A focus group study of adolescent girls' reasons for withdrawing from physical activity. Psychology of Sport and Exercise, 11(6), 619-626.

Telama, R., Yang, X., Viikari, J., Välimäki, I., Wanne, O., \& Raitakari, O. (2005). Physical activity from childhood to adulthood: a 21-year tracking study. American Journal of Preventive Medicine, 28(3), 267-273.

Trost, S. G., Pate, R. R., Sallis, J. F., Freedson, P. S., Taylor, W. C., Dowda, M., \& Sirard, J. (2002). Age and gender differences in objectively measured physical activity in youth. Medicine and Science in Sports and Exercise, 34(2), 350-355. 
Verghese, J., Lipton, R. B., Katz, M. J., Hall, C. B., Derby, C. A., Kuslansky, G., . . B Buschke, H. (2003). Leisure activities and the risk of dementia in the elderly. New England Journal of Medicine, 348(25), 2508-2516.

Wall, M. I., Carlson, S. A., Stein, A. D., Lee, S. M., \& Fulton, J. E. (2011). Trends by age in youth physical activity: Youth Media Campaign Longitudinal Survey. Medicine and Science in Sports and Exercise, 43(11), 2140-2147.

Way, R., Balyi, I. et al. (2019). Hockey Canada Development Program. Long Term Player Development. [online]. Retrieved [June, 2020] from https://cdn.hockeycanada.ca/hockey -canada/Hockey-Programs/Players/Downloads/2017/ltpd-multisport-e.pdf. 